\title{
Review Article \\ Redox Changes Induced by General Anesthesia in Critically Ill Patients with Multiple Traumas
}

\author{
Marius Papurica, ${ }^{1,2}$ Alexandru Florin Rogobete, ${ }^{1,2}$ Dorel Sandesc, ${ }^{1,2}$ \\ Raluca Dumache, ${ }^{2}$ Radu Nartita, ${ }^{3}$ Mirela Sarandan, ${ }^{4}$ Alina Carmen Cradigati, ${ }^{4}$ \\ Loredana Luca, ${ }^{1}$ Corina Vernic, ${ }^{2}$ and Ovidiu Horea Bedreag ${ }^{1,2}$ \\ ${ }^{1}$ Clinic of Anesthesia and Intensive Care, Emergency County Hospital "Pius Brinzeu", 300736 Timisoara, Romania \\ ${ }^{2}$ Faculty of Medicine, "Victor Babes" University of Medicine and Pharmacy, 300041 Timisoara, Romania \\ ${ }^{3}$ Faculty of Chemistry, Biology, Geography, West University of Timisoara, 300115 Timisoara, Romania \\ ${ }^{4}$ Clinic of Anesthesia and Intensive Care "Casa Austria", Emergency County Hospital "Pius Brinzeu", 300736 Timisoara, Romania \\ Correspondence should be addressed to Radu Nartita; nartita.radu@yahoo.com
}

Received 7 August 2015; Accepted 15 October 2015

Academic Editor: Sharad S. Singhal

Copyright (C) 2015 Marius Papurica et al. This is an open access article distributed under the Creative Commons Attribution License, which permits unrestricted use, distribution, and reproduction in any medium, provided the original work is properly cited.

\begin{abstract}
The critically ill polytrauma patient is a constant challenge for the trauma team due to the complexity of the complications presented. Intense inflammatory response and infections, as well as multiple organ dysfunctions, significantly increase the rate of morbidity and mortality in these patients. Moreover, due to the physiological and biochemical imbalances present in this type of patients, the bioproduction of free radicals is significantly accelerated, thus installing the oxidative stress. In the therapeutic management of such patients, multiple surgical interventions are required and therefore they are being subjected to repeated general anesthesia. In this paper, we want to present the pathophysiological implications of oxidative stress in critically ill patients with multiple traumas and the implications of general anesthesia on the redox mechanisms of the cell. We also want to summarize the antioxidant treatments able to reduce the intensity of oxidative stress by modulating the biochemical activity of some cellular mechanisms.
\end{abstract}

\section{Introduction}

The critically ill polytrauma patient requires a multidisciplinary management due to the complexity of injuries [1]. The most common injuries are represented by traumatic brain injury, spinal cord injury, traumatic injuries of the lung parenchyma, abdominal traumas, traumatic injuries of the pelvis and of extremities, and a number of phenomena that usually accompany the multiple traumas, such as hemorrhagic shock or hypothermia [2-4]. Moreover, a series of secondary injuries are installed after the primary injuries such as systemic inflammatory response syndrome (SIRS), sepsis, and eventually multiple organ dysfunction syndrome (MODS) [5, 6]. A high percentage of patients with multiple traumas are requiring emergency surgery at the admission time or several times during the length of stay in the intensive care unit (ICU). General anesthesia is required in order to ensure the need for the surgical interventions.
Numerous studies have highlighted a number of molecular changes induced by anesthetic substances, regarding the redox balance $[7,8]$. Due to hypermetabolism and due to severe generalized inflammations, the critically ill polytrauma patient shows a tropism for the aggressive production of free radicals (FR) ultimately responsible for the installation of the phenomenon called oxidative stress (OS) $[9,10]$.

In this paper, we want to present the pathophysiological implications of OS in the critically ill patient with multiple traumas, as well as its modulation by general anesthesia. We also want to summarize the existing antioxidant methods currently used to minimize OS in this type of patients.

\section{Biochemical and Pathophysiological Aspects of Oxidative Stress}

Due to the cell redox activity in physiological conditions, a series of highly reactive species called FR are being produced. 


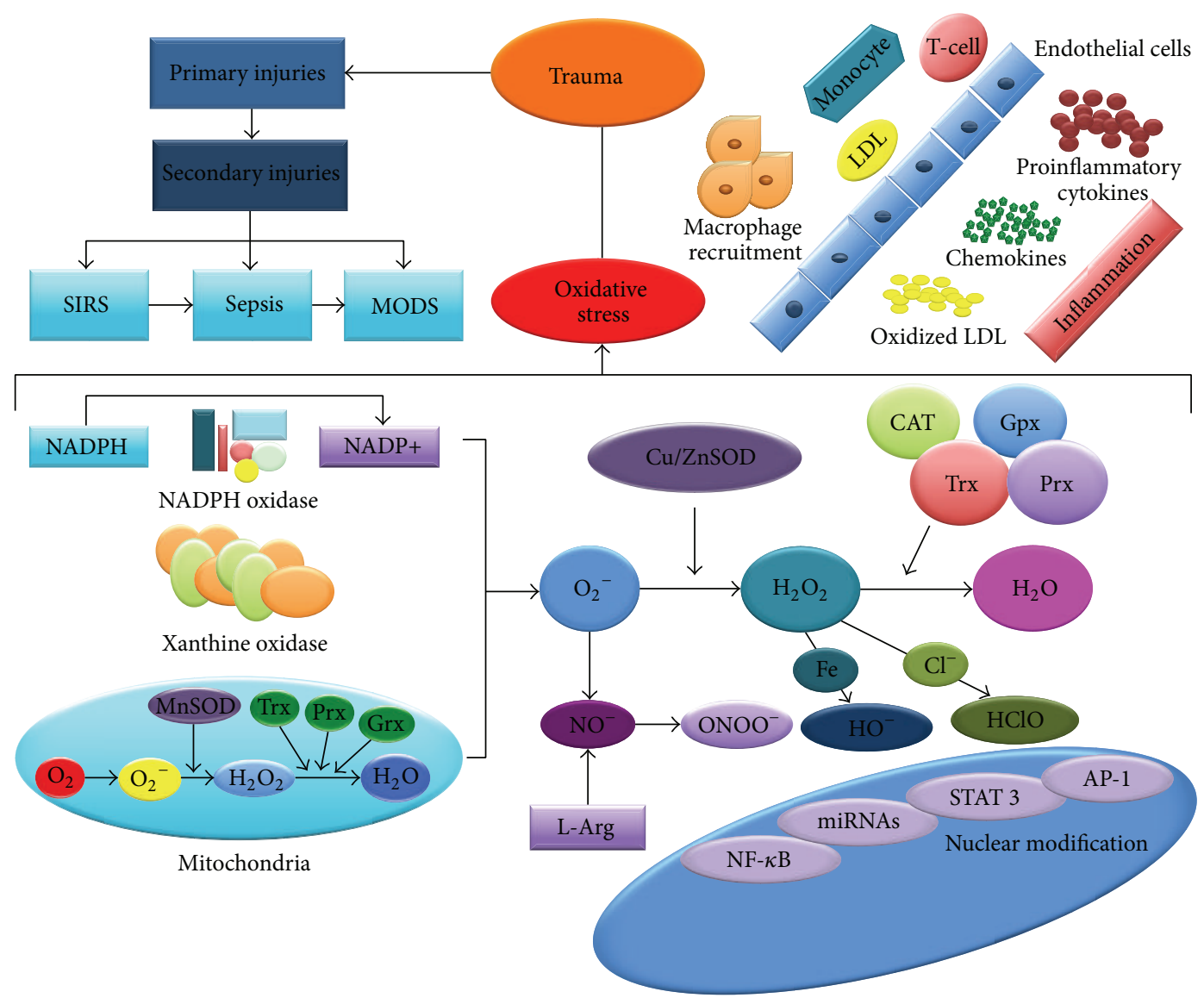

FIGURE 1: Schematic representation of oxidative stress in the critically ill patient with multiple traumas. Primary trauma induces a series of secondary injuries due to the biological and biochemical imbalances. The first side effect installed is SIRS, followed by sepsis, and finally by MODS. The inflammations generated by the action of the polymorphonuclear cells, as well as by hypermetabolism, maintain and enhance the oxidative stress. Mitochondria are significantly affected thereby producing significant amounts of superoxide anion. Free radicals produced at the cellular level are neutralized by the number of antioxidant enzyme systems, such as SOD, CAT, Trx, Gpx, and Prx [11, 12].

The most important FR classes are represented by reactive oxygen species (ROS), reactive nitrogen species (RNS), and reactive lipid species (RLS) [27-29]. The cell redox potential is influenced mostly by nicotinamide adenine dinucleotide phosphate (NADPH) oxidases, xanthine oxidase, cytochrome P450 isoenzymes, cyclooxygenase, endothelial NO synthase, lipoxygenase, and hemeoxygenase [30-32] (Figure 1).

FR oxidative activity is kept under control by endogenous antioxidant systems, represented by a number of antioxidant enzymes and some vitamins. The most potent endogenous antioxidant systems are represented by antioxidant enzymes, such as glutathione (GSH), thioredoxin (Trx), glutaredoxins (Grx), superoxide dismutase (SOD), catalase (CAT), paraoxonase (PON), and peroxiredoxins (Prx) $[20,22,33,34]$. In Table 1 the most important endogenous antioxidant systems are summarized.

In the critically ill polytrauma patient, the antioxidant/oxidant ratio is disrupted, thus the oxidative stress (OS) being installed (Figure 1). Along with increasing OS intensity, a number of cellular biological systems are disrupted because of DNA and protein distortion or because of lipoprotein membrane oxidation, resulting in the blockage of the cellular biochemical activity. The accelerated bioproduction of FR is involved in the DNA modulation reactions, the specific biomarkers in this regard being 8hydroxydeoxyguanosine (8-OHdG) [35]. For lipid oxidation, malondialdehyde (MDA), 4-hydroxynonenal (4-HNE), and isoprostanes (IsoPS) were identified and used as biomarkers [36]. Also, for protein oxidation, the carbonyl group and nitrotyrosine have been identified [37-40].

In the case of severe traumas, shortly after the traumatic injury, the systemic inflammatory response syndrome (SIRS) is installed [5]. Specialized studies have demonstrated that OS is responsible for the amplification of inflammations. From a genetic point of view, OS modulates the inflammation by regulating the activity of some transcription factors, such as nuclear factor-kappa B (NF- $\kappa \mathrm{B})$, signal transducer and activator of transcription 3 (STAT 3), hypoxia inducible factor 1-alpha (HIF-1-alpha), and activator protein-1 (AP-1) [32, 4144]. By stimulating the activity of these factors, the proinflammatory mediators are being excessively secreted. They are responsible for the dissemination and the enhancement of the 
TABLE 1: The most important endogenous antioxidant systems.

\begin{tabular}{|c|c|c|}
\hline Antioxidant system & Properties & Reference(s) \\
\hline GSH & $\begin{array}{l}\text { It is found in the extracellular environment as well as in the intracellular one } \\
\text { It forms disulfide bonds with other compounds } \\
\text { The redox activity is due mainly to the cysteine that it contains } \\
\text { Physiological ratio of the reduced form and oxidized form in the cytosol is } 50: 1 \text { and in the } \\
\text { endoplasmic reticulum } 2: 1\end{array}$ & {$[11,13,14]$} \\
\hline Grx & $\begin{array}{l}\text { It is part of the class thiol-disulfide oxidoreductases } \\
\text { Two forms were identified in the cytosol (Grxl) and mitochondria (Grx2) } \\
\text { Together with Trx, it modulates the cell redox activity }\end{array}$ & {$[15,16]$} \\
\hline $\operatorname{Tr} x$ & $\begin{array}{l}\text { Redox activity occurs through the action on the disulfide bonds } \\
\text { It intervenes in the oxidation of proteins } \\
\text { It intervenes in reducing hydroperoxides } \\
\text { It modulates the transcription factors } \\
\text { It intervenes in inactivating ROS }\end{array}$ & [17-19] \\
\hline SOD & $\begin{array}{l}\text { It is the main endogenous antioxidant system responsible for the inactivation of superoxide anion } \\
\text { Redox activity is made by connecting with other antioxidant enzymes, such as catalase } \\
\text { Two forms have been identified, one intracellular Cu/ZnSOD and one mitochondrial MnSOD }\end{array}$ & {$[20,21]$} \\
\hline CAT & $\begin{array}{l}\text { The main activity is the reduction of hydrogen peroxide to water and oxygen } \\
\text { It is located predominantly in peroxisomes }\end{array}$ & {$[11,22]$} \\
\hline $\operatorname{Prx}$ & $\begin{array}{l}\text { Reduced in general hydroperoxides } \\
15 \text { isoforms have been identified, from which only } 6 \text { were found in the human organism } \\
\text { Prx1, Prx2, and Prx6 in cytosol } \\
\text { Prx5 in mitochondria and cytosol } \\
\text { Prx3 in mitochondria } \\
\text { Prx4 in extracellular matrix }\end{array}$ & {$[22-25]$} \\
\hline PON & $\begin{array}{l}\text { Extracellular oxidative enzyme } \\
3 \text { forms have been identified in the human organism } \\
\text { PON1 prevents oxidation of LDL } \\
\text { PON2 predominantly intracellular antioxidant activity } \\
\text { PON3 is associated with the activity of HDL }\end{array}$ & {$[26]$} \\
\hline
\end{tabular}

GSH: glutathione; Grx: glutaredoxins; Trx: thioredoxin; SOD: superoxide dismutase; CAT: catalase; Prx: peroxiredoxin; PON: paraoxonase; LDL: low density lipoprotein; HDL: high density lipoprotein.

inflammatory response. NF- $\kappa \mathrm{B}$ is considered to be the most important transcription factor regarding the inflammatory response, being responsible for the excessive synthesis of some proinflammatory cytokines such as interleukin 1 (IL-1), interleukin 6 (IL-6), interleukin 8 (IL-8), and tumor necrosis factor-alpha (TNF-alpha) [45-47]. From a structural point of view, NF- $\kappa \mathrm{B}$ is composed of two subunits, p50 and p65. This is physiologically found in the cytoplasm, forming a complex with an inhibitory protein $(\mathrm{IkB})$. Along with the cell stimulation, IkB is phosphorylated in two residual groups of serine. OS favors the activation of the cell surface and therefore is modulating the activity of NF- $\kappa$ B in the nucleus $[27,48,49]$.

Specialized studies show a significant increase in morbidity and mortality at the polytrauma patients that have suffered from complications due to severe inflammations. One of the organs most affected in this regard is the lung. Thoracic trauma, according to the trauma reports, is one of the most prevalent in this type of patients [50]. Severe injuries of the pulmonary parenchyma are associated with an increased morbidity and mortality due to the primary injury as well as to the secondary complications. Among them, the most severe injuries are represented by the acute lung injury (ALI) and by the acute respiratory distress syndrome
(ARDS) [51, 52]. In these cases, not only because of the excessive production of proinflammatory molecules, but also because of the activation of the polymorphonuclear cells, OS is significantly intensified [53]. Another system significantly affected, especially in patients with hemorrhagic shock, is the microvascular system. This system is composed of small blood vessels with a diameter smaller than 100 microns, which are responsible for tissue oxygenation, nutrition, and immune modulation. Hemorrhagic shock, infections, and inflammations are leading to microcirculatory dysfunction. Induced endothelial dysfunction also leads to the excessive production of $\mathrm{FR}$ and therefore to the intensification and generalization of OS [54-56].

\section{Chemical Aspects of General Anesthetics}

The most commonly used substances in general anesthesia are volatile anesthetics, such as desflurane, halothane, isoflurane, and sevoflurane. Other anesthetics substances that are not volatile are also used in the present such as ketamine, midazolam, and propofol. Volatile anesthetics are from a chemical point of view halogenated substances. According to the International Union of Pure and Applied Chemistry 
(IUPAC, http://www.iupac.org/), desflurane is fluorinated ether with molecular formula 2-(difluoromethoxy)-1,1,1,2tetrafluoroethane. Halothane is a halogenated hydrocarbon anesthetic with molecular formula 2-bromo-2-chloro-1,1,1trifluoroethane. Isoflurane is a fluorinated ether with molecular formula 2-chloro-2-(difluoromethoxy)-1,1,1-trifluoroethane and sevoflurane is a fluorinated isopropyl ether with molecular formula 1,1,1,3,3,3-hexafluoro-2-(fluoromethoxy)propane [57-59]. Propofol belongs to the class of hypnotic alkylphenol derivatives, with molecular formula 2,6-di(propan-2-yl)phenol. Ketamine is a cyclohexanone derivative with anesthetic properties and with molecular formula 2-(2-chlorophenyl)-2-(methylamino)cyclohexan-1one. Midazolam is a benzodiazepine with molecular formula 8-chloro-6-(2-fluorophenyl)-1-methyl-4H-imidazo[1,5-a][1, 4]benzodiazepine (Figure 2) [60-62].

\section{Molecular Changes Induced by General Anesthesia}

Regarding the molecular changes induced by general anesthetics, there are a series of studies that highlight the implications of these substances in the cellular metabolisms. Morio et al. report in a study on biotransformation reactions of general anesthetics several FR species that resulted from specific metabolic reactions. The majority of general anesthetics are degraded by enzymatic systems such as cytochrome P450 located in cytoplasm and mitochondria [62-64]. The enzymatic reactions of degradation of anesthetic substances can be grouped in two phases, phase I of oxidation or reduction and phase II of conjugation or synthesis. In the study conducted by them on the biotransformation of halothane, they have identified a series of metabolic compounds responsible for enhancing and maintaining the OS. Chlorodifluoroethylene and chlorotrifluoromethane were found in the exhaled air and trifluoroacetic acid and fluoride ion were found in urine, blood, and saliva [65]. FR thus released interacts further with different biological systems, supporting the redox cycle of OS. Moreover, the critically ill polytrauma has a high level of OS in the time of surgery, thus increasing the redox activity (Figure 3).

Karabiyık et al. have studied the possible genotoxic effects of volatile anesthetics in patients who required general anesthesia. They studied two groups in which the general anesthesia was performed with isoflurane and sevoflurane, respectively. In both cases, they have detected changes in the DNA structure and function [66]. In a similar study conducted by Alleva et al., significant changes induced by sevoflurane on the structural integrity of DNA were reported. Moreover, they have observed a decrease in the concentration of GSH and an increased lymphocyte concentration in the first 24 hours postoperatively. This was correlated with a decrease in the body's antioxidant capacity, mostly induced by the proinflammatory activity of the general anesthetics used [67]. However, at the opposite side, Szyfter et al., in a similar study, have not identified significant genetic changes regarding sevoflurane [68]. Jin et al. have studied the inflammatory response caused by sevoflurane in comparison with the inflammatory response caused by propofol. In order to assess the inflammatory status, they have monitored a series of specific biomarkers such as TNF-alpha, IL-6, and IL10. Following their study, an increase of the systemic inflammatory response in critically ill patients who have received sevoflurane [69] was reported. Türkan et al. have conducted a similar study in which they have quantified the OS specific for erythrocytes in the case where general anesthesia was performed with sevoflurane and desflurane. Following their study, it was reported that sevoflurane has a greater impact on the cellular redox status in comparison with desflurane [70]. Zhang et al. have studied the effects of isoflurane and sevoflurane regarding the inflammatory response and the activity of the nuclear factor NF- $\kappa \mathrm{B}$ in neuroglioma cells. Following this study, they have reported significant increases in the concentrations of IL- 6 and NF- $\kappa \mathrm{B}$, thus explaining the possible neurotoxic effects induced by general anesthesia [71]. $\mathrm{NF}-\kappa \mathrm{B}$ increased activity, and, implicitly, the intensification of the inflammatory response induced by sevoflurane is also demonstrated by Li et al. in a similar study [72]. Liu et al. also demonstrate that sevoflurane is responsible for increasing the FR concentration and for altering the cell structure [73].

Although a number of specialized studies highlight the oxidative effects of general anesthetics, there are numerous studies that do not report significant redox changes, and even more they highlight a series of anti-inflammatory effects. Orosz et al. have studied and quantified a number of specific biomarkers for OS induced by general anesthesia, such as DNA damage or the body's antioxidant capacity. Following this study, significant changes regarding the cellular redox status were not identified [74]. Moreover, Schilling et al. have shown that sevoflurane is responsible for reducing the biosynthesis of proinflammatory molecules such as TNFalpha, IL-8, and IL-1 beta [75]. Crozier et al. also show that the use of propofol and alfentanil decreases the serum levels of proinflammatory cytokines [76]. Shen et al. have identified the influence of isoflurane on the redox status of the heart muscle, reporting some cardioprotective effects [77]. Li et al. have examined the effects induced by isoflurane regarding inflammations in laboratory animals, observing a decrease of the proinflammatory factors in the lung tissue. They have also showed that neutrophils have a minimized capacity of penetration into the lung parenchyma, being responsible for reducing the production of proinflammatory cytokines. Following this study, the authors concluded a decrease of NF$\kappa \mathrm{B}$ nuclear signals induced by isoflurane [78].

Numerous studies report the cardioprotective effects of volatile general anesthetics. They are able to dilate the coronary arteries by decreasing the influx of $\mathrm{Ca}^{2+}$ through the voltage-dependent calcium channels in the vascular smooth muscle. In addition, it was reported that halothane and desflurane increase the release of nitric oxide in the coronary arteries. Another protective effect attributed to volatile anesthetics is the anti-ischemic protection mechanisms through the conservation of adenosine triphosphate (ATP) [79]. During ischemia, ATP is degraded resulting in metabolites such as adenosine, hypoxanthine, inosine, and certain purine derivatives, which diffuse rapidly through the cell membrane. In numerous studies, significant metabolic changes caused by ischemia in the myocardium of laboratory animals treated 


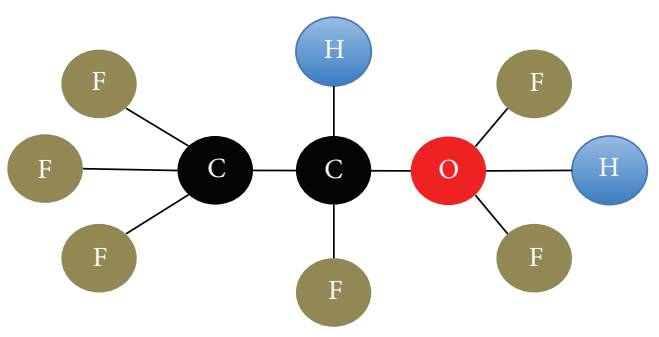

(a)

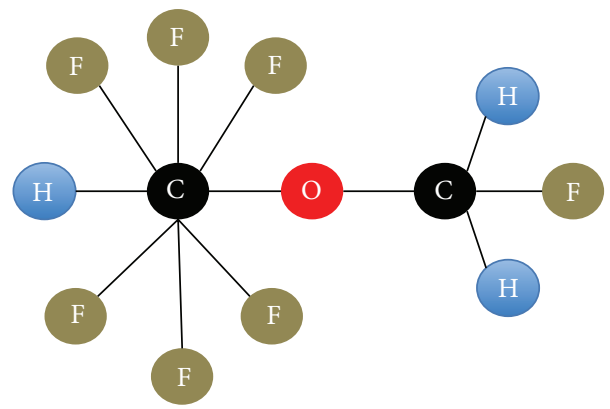

(c)

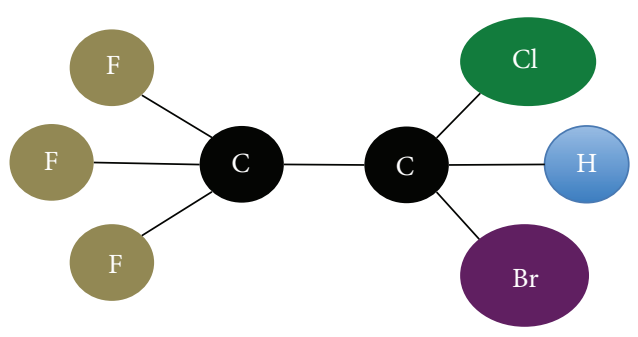

(b)

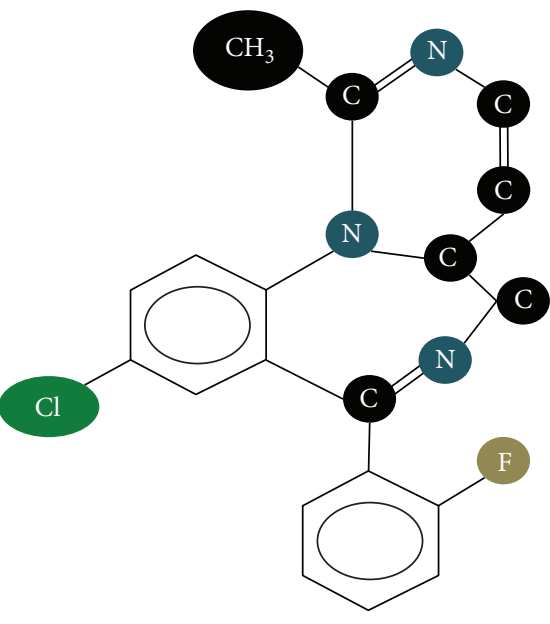

(f)

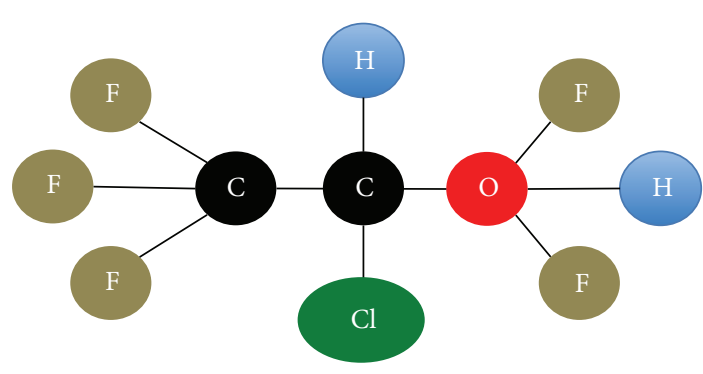

(d)

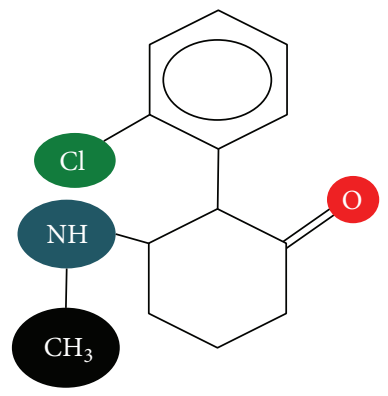

(e)

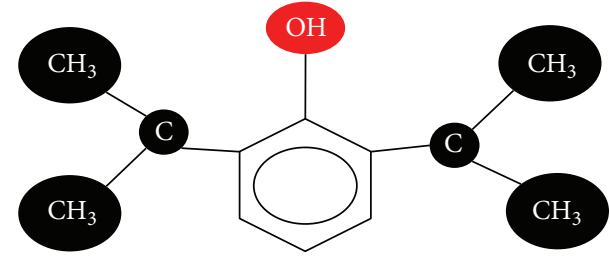

(g)

Figure 2: The chemical structure of (a) desflurane, (b) halothane, (c) isoflurane, (d) sevoflurane, (e) ketamine, (f) midazolam, and (g) propofol.

with volatile anesthetics were highlighted. The mechanism by which volatile anesthetics help in maintaining the ATP reserves is not known, but most likely it involves increasing its synthesis [80, 81].

One of the main factors responsible for the mechanical postischemic dysfunction is represented by the alteration of the intracellular calcium concentration, given that both ischemia and reperfusion are inducing calcium overload. Increasing the intracellular calcium levels induced a change regarding the sensitivity of the contractile apparatus by decreasing the myofilaments sensitivity to calcium ions, thus a prolonged depression of the myocardial contractility being installed. The effects of anesthetics on the cardiovascular system are the consequence of their action on the calcium channel, where they cause inhibition of the atrioventricular node, prolongation of the atrioventricular conduction, and decreased myocardial contractility $[80,82]$.
Regarding the nuclear changes induced by general anesthetics, a series of studies regarding the expression of miRNAs [83] were performed. From a structural point of view, miRNAs are short RNA species composed of 19 to 24 nucleotides on average. miRNAs genesis begins in the nucleus with the action of RNA polymerase II on a protein-coding. This forms a first species, called pri-miRNA. Through successive reactions of polyadenylation, the precursor of miRNAs, called pre-miRNA, is obtained. The new formed pre-miRNA is transported into the cytoplasm through Exportin 5. In the cytoplasm, on the pre-miRNA, the Dicer complex acts forming double stranded mature miRNA (19-24 nucleotides) and miRNA* (passenger strand) (Figure 4) [84-87]. Kim et al. have studied the effects induced by propofol on miRNAs expression. The results are presented in Table 2.

Tanaka et al. have also identified a number of changes in the expression of miRNAs after the administration of 


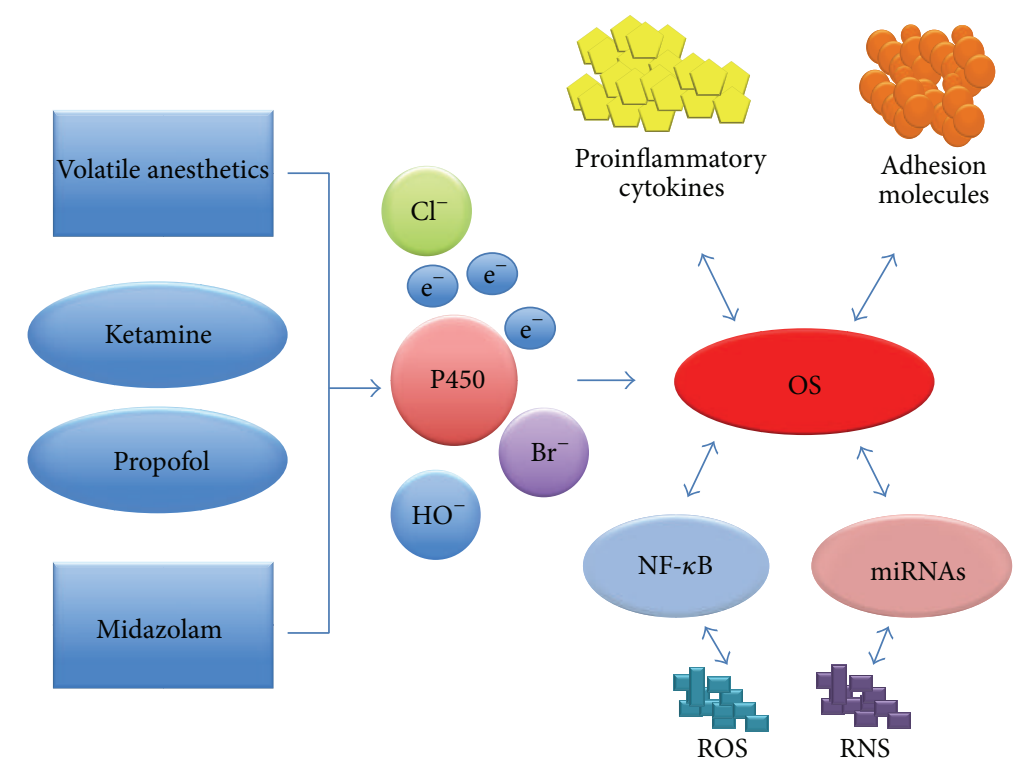

FIgURE 3: The implications of general anesthetics in the cellular redox activity.

TABLE 2: miRNAs expression in patients who have received propofol.

\begin{tabular}{|c|c|c|}
\hline miRNAs & Expression & Reference(s) \\
\hline $\begin{array}{l}\text { miRNA-204, miRNA-92b, miRNA-30b, miRNA-127, miRNA-296-5p, miRNA-192, miRNA-26b, miRNA-25, } \\
\text { miRNA-186, miRNA-191, miRNA-368, miRNA-194, miRNA-199a, miRNA-23b, miRNA-133a, miRNA-219-5p, } \\
\text { miRNA-101, and miRNA-27a }\end{array}$ & Decreased & [88] \\
\hline $\begin{array}{l}\text { miRNA-29b, miRNA-216a, miRNA-190b, miRNA-let-7c, miRNA-92a, miRNA-202, miRNA-140-3p, } \\
\text { miRNA-198, miRNA-127-5p, miRNA-424, miRNA-193a-5p, miRNA-371-5p, miRNA-107, miRNA-296-3p, } \\
\text { miRNA-143, miRNA-143, miRNA-let-7b, miRNA-30d, miRNA-302a, miRNA-103, miRNA-206-3, miRNA-153, } \\
\text { miRNA-181d, miRNA-370, miRNA-134, miRNA-142-5p, miRNA-185, miRNA-1-let-7e, and miRNA-208b }\end{array}$ & Increased & [88] \\
\hline
\end{tabular}

propofol and sevoflurane. It was reported that propofol induces modifications of the miRNAs expression in a higher percentage than sevoflurane [89]. Twaroski et al. report changes in the expression of miRNA-21 when propofol is administered [90]. Another substance commonly used in the clinical practice in order to achieve sedation and anesthesia is ketamine. This is a noncompetitive antagonist of the NMDA receptors. Ketamine metabolic pathway is similar to that of cocaine, being a produced series of FR [91, 92]. Abdel-Salam et al. have studied the effects induced by ketamine on OS and on the inflammatory response, reporting significant increases of TNF-alpha in the brain [93]. Sinner et al. show an increase in the concentration of cytoplasmic $\mathrm{Ca}^{2+}$ in brain and an increased incidence of neuronal apoptosis when anesthesia is performed with ketamine [94]. Another molecular change in the patients who have received anesthesia is represented by the epigenetic changes. Affecting the methylation mechanism of DNA-histone chromatin complex is excessively producing a series of proinflammatory factors. Also the nuclear transcription mechanisms and the endogenous production mechanisms of some proteins are being significantly affected [95].

\section{Antioxidant Therapy}

Numerous studies present the molecular modifications induced by excessive free radicals. The physiological and biochemical modifications induced by free radicals are represented by an energetic mitochondrial imbalance, as well as a disrupted antioxidant capacity.

Lately, there have been a number of studies on minimizing the OS in critically ill polytrauma patients [15, 96]. A number of substances with high antioxidant activity were intensively studied, which include vitamin C, vitamin E, and $\mathrm{N}$-acetylcysteine. Given the biological and biochemical changes induced by the direct trauma, the posttraumatic secondary injuries, and general anesthesia, implementing an antioxidant therapy is necessary in order to minimize OS. Nathens et al. have studied the effects of antioxidant therapy in the critically ill patients on a series of clinical aspects. The antioxidant therapy applied by them consisted in vitamin C $1000 \mathrm{mg}$ three times per day and $1000 \mathrm{IU}$ of vitamin E three times per day. Following this study, they have observed a decrease in morbidity and mortality, a lower incidence of MODS, a decrease of pulmonary complications, and 


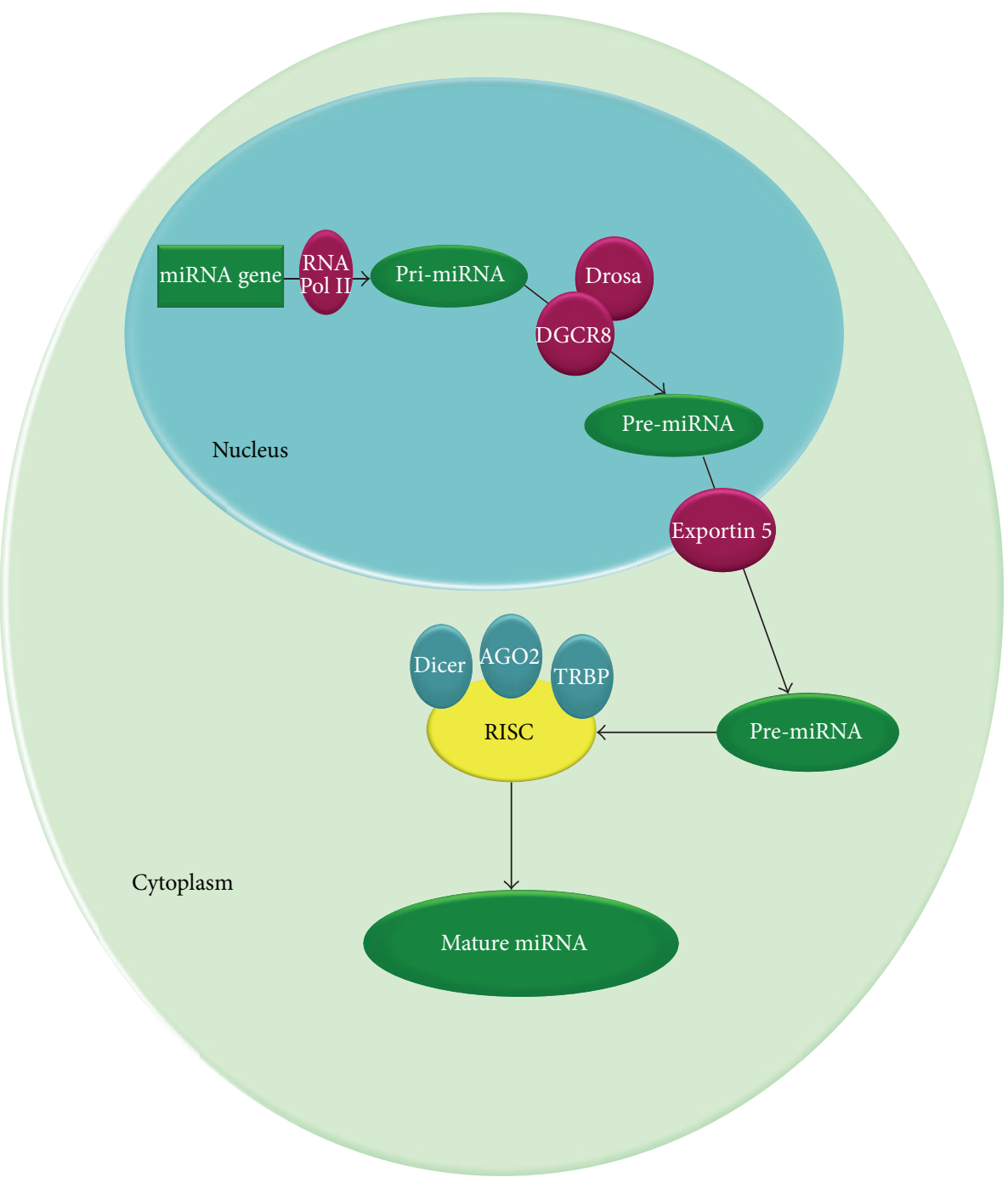

FIGURE 4: Biogenesis mechanism for miRNAs. The synthesis of miRNAs begins in the nucleus with the action of RNA polymerase II on a protein-coding. This forms a first species, called pri-miRNA. Through successive reactions of polyadenylation catalyzed by DGCR8 and Drosa, the precursor for the miRNAs species, called pre-miRNA, is obtained. pre-miRNA thus formed is transported into the cytoplasm through Exportin 5. In the cytoplasm, on the pre-miRNA acts the Dicer complex. Subsequently through the action of TRBP, AGO2 and Dicer is obtained the RNA induced silencing complex (RISC) and finnaly the mature miRNAs.

implicitly a decrease of the ventilation time [53]. Crimi et al. have also studied the effects of antioxidant therapy on the critical patient. They have administered $500 \mathrm{mg} /$ day of vitamin $\mathrm{C}$ and $400 \mathrm{IU} /$ day of vitamin E. Following their study, a decrease in mortality and in the ventilation time was highlighted [97]. Collier et al. conducted a similar study in which they have reported a decrease in the length of stay in ICU and in the hospital, as well as a decrease in mortality. The antioxidant therapy implemented by them was composed of vitamin $\mathrm{C}$ $1000 \mathrm{mg}$ three times per day, $1000 \mathrm{IU}$ of vitamin $\mathrm{E}$ three times per day, and $200 \mu \mathrm{g}$ of selenium [98]. Fukushima and Yamazaki confirm the antioxidant and anti-inflammatory effects of vitamin $\mathrm{C}$ administered shortly postsurgically in critically ill patients with multiple traumas [99].
Another substance with high antioxidant capacity commonly used in clinical practice is $\mathrm{N}$-acetylcysteine. Specialized studies confirm the antioxidant implications of $\mathrm{N}$ acetylcysteine in the critically ill and its effects of minimizing OS and the inflammatory response. Saad et al. in a study regarding the antioxidant action of $\mathrm{N}$-acetylcysteine confirm a decrease of OS along with the implementation of $\mathrm{N}$ acetylcysteine antioxidant therapy [100]. Inci et al. in a similar study, but performed on patients with lung transplant, confirm that the administration of $\mathrm{N}$-acetylcysteine protects the lung from ischemia through reperfusion and thus minimizes the systemic inflammatory response and reduces the intensity of OS [101]. In the specialized literature, there are a number of other studies regarding the antioxidant therapy applied in 
the critically ill polytrauma patients $[102,103]$. Optimizing the dosage and choosing the type of substance for each type of pathology still need to be researched.

\section{Conclusions}

The biochemical implications of general anesthetics on the cellular redox mechanisms are somewhat contradictory. There are studies that emphasize the oxidative effects of anesthetic agents and a number of studies that report antioxidative characteristics. Since general anesthesia is necessary for the appropriate therapeutic management of the critically ill polytrauma patient, more intensive research is required regarding the general anesthetics redox activity. Also, a more complex research regarding the optimization of antioxidant therapy is required.

However, following the study conducted, we can affirm that the administration of substances with antioxidant capacity to the critically ill patients with multiple traumas can make great improvements to their clinical evolution.

Other studies on the molecular modifications induced by anesthesia regarding the oxidative stress in critically ill patients are required. Also, studies regarding the antioxidant therapy in patients who receive anesthesia are required.

\section{Conflict of Interests}

The authors declare that there is no conflict of interests regarding the publication of this paper.

\section{Acknowledgment}

The authors wish to thank the Emergency County Hospital "Pius Brinzeu" Timisoara, for their support in conceiving this work.

\section{References}

[1] C. A. Adams, "Sepsis biomarkers in polytrauma patients," Critical Care Clinics, vol. 27, no. 2, pp. 345-354, 2011.

[2] J. O. Barbosa Neto, M. F. Breda de Moraes, R. Souza Nani, J. A. Rocha Filho, and M. J. Carvalho Carmona, "Hemostatic resuscitation in traumatic hemorrhagic shock: case report," Revista Brasileira de Anestesiologia, vol. 63, no. 1, pp. 99-106, 2013.

[3] S. Wutzler, A. Wafaisade, M. Maegele et al., "Lung Organ Failure Score (LOFS): probability of severe pulmonary organ failure after multiple injuries including chest trauma," Injury, vol. 43, no. 9, pp. 1507-1512, 2012.

[4] M. Leenen, A. Scholz, R. Lefering, and S. Flohé, "Limited volume resuscitation in hypotensive elderly multiple trauma is safe and prevents early clinical dilutive coagulopathy-a matched pair analysis from TraumaRegister DGU," Injury, vol. 45, supplement 3, pp. S59-S63, 2014.

[5] V. Ciriello, S. Gudipati, P. Z. Stavrou, N. K. Kanakaris, M. C. Bellamy, and P. V. Giannoudis, "Biomarkers predicting sepsis in polytrauma patients: current evidence," Injury, vol. 44, no. 12, pp. 1680-1692, 2013.

[6] M. Burkhardt, U. Nienaber, A. Pizanis et al., "Acute management and outcome of multiple trauma patients with pelvic disruptions," Critical Care, vol. 16, no. 4, article R163, 2012.
[7] M. Erbas, Y. Demiraran, H. A. Yildirim et al., "Comparison of effects on the oxidant/antioxidant system of sevoflurane, desflurane and propofol infusion during general anesthesia," Brazilian Journal of Anesthesiology, vol. 65, no. 1, pp. 68-72, 2015.

[8] T. Kikuchi, H. Tan, T. Mihara et al., "Effects of volatile anesthetics on the circadian rhythms of rat hippocampal acetylcholine release and locomotor activity," Neuroscience, vol. 237, pp. 151160, 2013.

[9] R. Malaviya, J. D. Laskin, and D. L. Laskin, "Oxidative stressinduced autophagy: role in pulmonary toxicity," Toxicology and Applied Pharmacology, vol. 275, no. 2, pp. 145-151, 2014.

[10] G. J. Burton and E. Jauniaux, "Oxidative stress," Best Practice and Research: Clinical Obstetrics and Gynaecology, vol. 25, no. 3, pp. 287-299, 2011.

[11] F. Nogales, M. L. Ojeda, M. Fenutría, M. L. Murillo, and O. Carreras, "Role of selenium and glutathione peroxidase on development, growth, and oxidative balance in rat offspring," Reproduction, vol. 146, no. 6, pp. 659-667, 2013.

[12] B.-J. Lee, J.-S. Lin, Y.-C. Lin, and P.-T. Lin, "Effects of Lcarnitine supplementation on oxidative stress and antioxidant enzymes activities in patients with coronary artery disease: a randomized, placebo-controlled trial," Nutrition Journal, vol. 13, no. 1, article 79, 2014.

[13] R. Schnabel, K. J. Lackner, H. J. Rupprecht et al., "Glutathione peroxidase- 1 and homocysteine for cardiovascular risk prediction: results from the atherogene study," Journal of the American College of Cardiology, vol. 45, no. 10, pp. 1631-1637, 2005.

[14] S. C. Lu, "Glutathione synthesis," Biochimica et Biophysica Acta-General Subjects, vol. 1830, pp. 3143-3153, 2012.

[15] J. Wu, J. G. Hecker, and N. Chiamvimonvat, "Antioxidant enzyme gene transfer for ischemic diseases," Advanced Drug Delivery Reviews, vol. 61, no. 4, pp. 351-363, 2009.

[16] R. K. Jain, G. B. Singh, A. P. Singh, R. K. Goel, N. C. Aryya, and S. K. Jha, "Role of measurement of antioxidant enzymes in evaluation of antioxidant therapy in tobacco abusers with oral leukoplakia," Indian Journal of Otolaryngology and Head and Neck Surgery, vol. 63, no. 4, pp. 336-342, 2011.

[17] A. S. De Freitas and J. B. T. Rocha, "Diphenyl diselenide and analogs are substrates of cerebral rat thioredoxin reductase: a pathway for their neuroprotective effects," Neuroscience Letters, vol. 503, no. 1, pp. 1-5, 2011.

[18] F. W. Hoffmann, A. S. Hashimoto, B. C. Lee, A. H. Rose, R. V. Shohet, and P. R. Hoffmann, "Specific antioxidant selenoproteins are induced in the heart during hypertrophy," Archives of Biochemistry and Biophysics, vol. 512, no. 1, pp. 38-44, 2011.

[19] H. R. Griffiths, I. H. K. Dias, R. S. Willetts, and A. Devitt, "Redox regulation of protein damage in plasma," Redox Biology, vol. 2, no. 1, pp. 430-435, 2014.

[20] A.-F. Miller, "Superoxide dismutases: ancient enzymes and new insights," FEBS Letters, vol. 586, no. 5, pp. 585-595, 2012.

[21] M. Pilon, K. Ravet, and W. Tapken, "The biogenesis and physiological function of chloroplast superoxide dismutases," Biochimica et Biophysica Acta, vol. 1807, no. 8, pp. 989-998, 2011.

[22] I. Rahman and I. M. Adcock, "Oxidative stress and redox regulation of lung inflammation in COPD," European Respiratory Journal, vol. 28, no. 1, pp. 219-242, 2006.

[23] H. Steinbrenner and H. Sies, "Selenium homeostasis and antioxidant selenoproteins in brain: implications for disorders in the central nervous system," Archives of Biochemistry and Biophysics, vol. 536, no. 2, pp. 152-157, 2013. 
[24] I. M. Sab, M. M. D. Ferraz, T. A. S. Amaral et al., "Prenatal hypoxia, habituation memory and oxidative stress," Pharmacology Biochemistry and Behavior, vol. 107, pp. 24-28, 2013.

[25] T. I. Omotayo, G. S. Akinyemi, P. A. Omololu et al., "Possible involvement of membrane lipids peroxidation and oxidation of catalytically essential thiols of the cerebral transmembrane sodium pump as component mechanisms of iron-mediated oxidative stress-linked dysfunction of the pump's activity," Redox Biology, vol. 4, pp. 234-241, 2015.

[26] E. Agacayak, S. Basaranoglu, S. Tunc et al., "Oxidant/antioxidant status, paraoxonase activity, and lipid profile in plasma of ovariectomized rats under the influence of estrogen, estrogen combined with progesterone, and genistein," Drug Design, Development and Therapy, vol. 9, pp. 2975-2982, 2015.

[27] J. W. Horton, "Free radicals and lipid peroxidation mediated injury in burn trauma: the role of antioxidant therapy," Toxicology, vol. 189, no. 1-2, pp. 75-88, 2003.

[28] H. Kim, S. Bae, Y. Kim et al., "Vitamin C prevents stress-induced damage on the heart caused by the death of cardiomyocytes, through down-regulation of the excessive production of catecholamine, TNF- $\alpha$, and ROS production in Gulo(-/-) Vit Cinsufficient mice," Free Radical Biology and Medicine, vol. 65, pp. 573-583, 2013.

[29] H. M. Oudemans-van Straaten, A. M. E. Spoelstra-de Man, and M. C. de Waard, "Vitamin C revisited," Critical Care, vol. 18, no. 4, article 460, 2014.

[30] G. S. Aly, A. H. Shaalan, M. K. Mattar, H. H. Ahmed, M. E. Zaki, and H. R. Abdallah, "Oxidative stress status in nutritionally stunted children," Egyptian Pediatric Association Gazette, vol. 62, no. 1, pp. 28-33, 2014.

[31] A. Sureshbabu, S. W. Ryter, and M. E. Choi, "Oxidative stress and autophagy: crucial modulators of kidney injury," Redox Biology, vol. 4, pp. 208-214, 2015.

[32] B. M. Hybertson, B. Gao, S. K. Bose, and J. M. McCord, "Oxidative stress in health and disease: the therapeutic potential of Nrf2 activation," Molecular Aspects of Medicine, vol. 32, no. 46, pp. 234-246, 2011.

[33] C. Pugliese, R. V. Patin, C. Z. Palchetti et al., "Assessment of antioxidants status and superoxide dismutase activity in HIVinfected children," Brazilian Journal of Infectious Diseases, vol. 18, no. 5, pp. 481-486, 2014.

[34] R. Schmatz, L. B. Perreira, N. Stefanello et al., "Effects of resveratrol on biomarkers of oxidative stress and on the activity of $\Delta$ aminolevulinic acid dehydratase in liver and kidney of streptozotocin-induced diabetic rats," Biochimie, vol. 94, no. 2, pp. 374-383, 2012.

[35] C.-Y. Ock, E.-H. Kim, D. J. Choi, H. J. Lee, K.-B. Hahm, and M. H. Chung, "8-Hydroxydeoxyguanosine: not mere biomarker for oxidative stress, but remedy for oxidative stress-implicated gastrointestinal diseases," World Journal of Gastroenterology, vol. 18, no. 4, pp. 302-308, 2012.

[36] E. Nobécourt, S. Jacqueminet, B. Hansel et al., "Defective antioxidative activity of small dense HDL3 particles in type 2 diabetes: relationship to elevated oxidative stress and hyperglycaemia," Diabetologia, vol. 48, no. 3, pp. 529-538, 2005.

[37] S. B. Moussa, I. Sfaxi, Z. Tabka, H. B. Saad, and S. Rouatbi, "Oxidative stress and lung function profiles of male smokers free from COPD compared to those with COPD: a case-control study," Libyan Journal of Medicine, vol. 9, no. 1, pp. 1-13, 2014.

[38] H. O. Vargas, S. O. V. Nunes, M. R. P. de Castro et al., "Oxidative stress and inflammatory markers are associated with depression and nicotine dependence," Neuroscience Letters, vol. 544, pp. 136-140, 2013.

[39] M. D. Paidi, J. G. Schjoldager, J. Lykkesfeldt, and P. TvedenNyborg, "Prenatal vitamin $\mathrm{C}$ deficiency results in differential levels of oxidative stress during late gestation in foetal guinea pig brains," Redox Biology, vol. 2, no. 1, pp. 361-367, 2014.

[40] I. Galan-Chilet, M. Tellez-Plaza, E. Guallar et al., "Plasma selenium levels and oxidative stress biomarkers: a geneenvironment interaction population-based study," Free Radical Biology and Medicine, vol. 74, pp. 229-236, 2014.

[41] A. Szanto, B. L. Balint, Z. S. Nagy et al., "STAT6 transcription factor is a facilitator of the nuclear receptor PPAR $\gamma$-regulated gene expression in macrophages and dendritic cells," Immunity, vol. 33, no. 5, pp. 699-712, 2010.

[42] A. O. Estevez, K. L. Morgan, N. J. Szewczyk, D. Gems, and M. Estevez, "The neurodegenerative effects of selenium are inhibited by FOXO and PINK1/PTEN regulation of insulin/insulinlike growth factor signaling in Caenorhabditis elegans," NeuroToxicology, vol. 41, pp. 28-43, 2014.

[43] Y. Li, X. Liu, T. Zhou et al., "Inhibition of APE1/Ref-1 redox activity rescues human retinal pigment epithelial cells from oxidative stress and reduces choroidal neovascularization," Redox Biology, vol. 2, no. 1, pp. 485-494, 2014.

[44] M. Yamamoto, A. Singh, F. Sava, M. Pui, S. J. Tebbutt, and C. Carlsten, "MicroRNA expression in response to controlled exposure to diesel exhaust: attenuation by the antioxidant $\mathrm{N}$ acetylcysteine in a randomized crossover study," Environmental Health Perspectives, vol. 121, no. 6, pp. 670-675, 2013.

[45] T. Liu, Z. Fei, K. J. Gangavarapu et al., "Interleukin-6 and JAK2/STAT3 signaling mediate the reversion of dexamethasone resistance after dexamethasone withdrawal in 7TD1 multiple myeloma cells," Leukemia Research, vol. 37, no. 10, pp.1322-1328, 2013.

[46] O. Erbaş and D. Taşkiran, "Sepsis-induced changes in behavioral stereotypy in rats; Involvement of tumor necrosis factor$\alpha$, oxidative stress, and dopamine turnover," Journal of Surgical Research, vol. 186, no. 1, pp. 262-268, 2014.

[47] F. G. Zampieri, J. A. Kellum, M. Park et al., "Relationship between acid-base status and inflammation in the critically ill," Critical Care, vol. 18, article R154, 2014.

[48] J.-C. Liao, J.-S. Deng, C.-S. Chiu et al., "Anti-inflammatory activities of Cinnamomum cassia constituents in vitro and in vivo," Evidence-Based Complementary and Alternative Medicine, vol. 2012, Article ID 429320, 12 pages, 2012.

[49] Q. Huang, B. Gao, Q. Jie et al., "Ginsenoside-Rb2 displays antiosteoporosis effects through reducing oxidative damage and bone-resorbing cytokines during osteogenesis," Bone, vol. 66, pp. 306-314, 2014.

[50] S. Huber, P. Biberthaler, P. Delhey et al., "Predictors of poor outcomes after significant chest trauma in multiply injured patients: a retrospective analysis from the German Trauma Registry (Trauma Register DGU)," Scandinavian Journal of Trauma, Resuscitation and Emergency Medicine, vol. 22, no. 1, article 52, 2014.

[51] A. Gómez-Caro, J. R. Badia, and P. Ausin, "Extracorporeal lung assist in severe respiratory failure and ARDS. Current situation and clinical applications," Archivos de Bronconeumologia, vol. 46, no. 10, pp. 531-537, 2010.

[52] D. Salman, S. J. Finney, and M. J. D. Griffiths, "Strategies to reduce ventilator-associated lung injury (VALI)," Burns, vol. 39, no. 2, pp. 200-211, 2013. 
[53] A. B. Nathens, M. J. Neff, G. J. Jurkovich et al., "Randomized, prospective trial of antioxidant supplementation in critically ill surgical patients," Annals of Surgery, vol. 236, no. 6, pp. 814-822, 2002.

[54] C. Ince, "The microcirculation is the motor of sepsis," Critical Care, vol. 9, supplement 4, pp. S13-S19, 2005.

[55] F. Hildebrand, P. Radermacher, S. Ruchholtz et al., "Relevance of induced and accidental hypothermia after traumahaemorrhage-what do we know from experimental models in pigs?" Intensive Care Medicine Experimental, vol. 2, article 16, 2014.

[56] Z. Wang, J. H. Holthoff, K. A. Seely et al., "Development of oxidative stress in the peritubular capillary microenvironment mediates sepsis-induced renal microcirculatory failure and acute kidney injury," American Journal of Pathology, vol. 180, no. 2, pp. 505-516, 2012.

[57] A. Karci, S. Duru, H. Hepağuşlar, L. Çiftçi, and O. Yilmaz, "Comparison of the effect of sevoflurane and propofol on oxygenation during gradual transition to one-lung ventilation," Brazilian Journal of Anesthesiology, vol. 64, no. 2, pp. 79-83, 2014.

[58] R. M. Smiley, E. Ornstein, E. J. Pantuck, C. B. Pantuck, and R. S. Matteo, "Metabolism of desflurane and isoflurane to fluoride ion in surgical patients," Canadian Journal of Anaesthesia, vol. 38, no. 8, pp. 965-968, 1991.

[59] M. Schläpfer, T. Piegeler, R. O. Dull et al., "Propofol increases morbidity and mortality in a rat model of sepsis," Critical Care, vol. 19, article 45, 12 pages, 2015.

[60] A. A. Abdellatif, R. H. Elkabarity, and T. A. E. Hamdy, "Dexmedetomedine vs midazolam sedation in middle ear surgery under local anesthesia: effect on surgical field and patient satisfaction," Egyptian Journal of Anaesthesia, vol. 28, no. 2, pp. 117-123, 2012.

[61] M. Krzisch, S. Sultan, J. Sandell, K. Demeter, L. Vutskits, and N. Toni, "Propofol anesthesia impairs the maturation and survival of adult-born hippocampal neurons," Anesthesiology, vol. 118, no. 3, pp. 602-610, 2013.

[62] N. Kotani and N. Akaike, "The effects of volatile anesthetics on synaptic and extrasynaptic GABA-induced neurotransmission," Brain Research Bulletin, vol. 93, pp. 69-79, 2013.

[63] D. K. Spracklin, D. C. Hankins, J. M. Fisher, K. E. Thummel, and E. D. Kharasch, "Cytochrome P450 2E1 is the principal catalyst of human oxidative halothane metabolism in vitro," Journal of Pharmacology and Experimental Therapeutics, vol. 281, no. 1, pp. 400-411, 1997.

[64] S. Bansal, G. Biswas, and N. G. Avadhani, "Mitochondriatargeted heme oxygenase-1 induces oxidative stress and mitochondrial dysfunction in macrophages, kidney fibroblasts and in chronic alcohol hepatotoxicity," Redox Biology, vol. 2, no. 1, pp. 273-280, 2014.

[65] M. Morio, O. Yuge, and K. Fujii, "Biotransformation and toxicity of inhalational anaesthetics," Canadian Journal of Anaesthesia, vol. 37, no. 1, 1990.

[66] L. Karabıyık, S. Şardaş, U. Polat, N. A. KocabaŞ, and A. E. Karakaya, "Comparison of genotoxicity of sevoflurane and isoflurane in human lymphocytes studied in vivo using the comet assay," Mutation Research/Genetic Toxicology and Environmental Mutagenesis, vol. 492, no. 1-2, pp. 99-107, 2001.

[67] R. Alleva, M. Tomasetti, M. D. Solenghi et al., "Lymphocyte DNA damage precedes DNA repair or cell death after orthopaedic surgery under general anaesthesia," Mutagenesis, vol. 18, no. 5, pp. 423-428, 2003.
[68] K. Szyfter, R. Szulc, A. Mikstacki, I. Stachecki, M. Rydzanicz, and P. Jałoszyński, "Genotoxicity of inhalation anaesthetics: DNA lesions generated by sevoflurane in vitro and in vivo," Journal of Applied Genetics, vol. 45, no. 3, pp. 369-374, 2004.

[69] Y. Jin, X. Zhao, H. Li, Z. Wang, and D. Wang, "Effects of sevofurane and propofol on the inflammatory response and pulmonary function of perioperative patients with one-lung ventilation," Experimental and Therapeutic Medicine, vol. 6, no. 3, pp. 781-785, 2013.

[70] H. Türkan, A. Aydin, A. Sayal, and B. Karahalil, “The effect of sevoflurane and desflurane on markers of oxidative status in erythrocyte," Toxicology and Industrial Health, vol. 27, no. 2, pp. 181-186, 2011.

[71] L. Zhang, J. Zhang, L. Yang, Y. Dong, Y. Zhang, and Z. Xie, "Isoflurane and sevoflurane increase interleukin-6 levels through the nuclear factor-kappa B pathway in neuroglioma cells," British Journal of Anaesthesia, vol. 110, no. 1, pp. 21-26, 2013.

[72] Z.-Q. Li, X.-Y. Rong, Y.-J. Liu et al., "Activation of the canonical nuclear factor $-\kappa \mathrm{B}$ pathway is involved in isoflurane-induced hippocampal interleukin- $1 \beta$ elevation and the resultant cognitive deficits in aged rats," Biochemical and Biophysical Research Communications, vol. 438, no. 4, pp. 628-634, 2013.

[73] B. Liu, Y. Gu, H. Xiao, X. Lei, W. Liang, and J. Zhang, "Altered metabolomic profiles may be associated with sevofluraneinduced neurotoxicity in neonatal rats," Neurochemical Research, vol. 40, no. 4, pp. 788-799, 2015.

[74] J. E. B. Orosz, L. G. Braz, A. L. A. Ferreira et al., "Balanced anesthesia with sevoflurane does not alter redox status in patients undergoing surgical procedures," Mutation ResearchGenetic Toxicology and Environmental Mutagenesis, vol. 773, pp. 29-33, 2014.

[75] T. Schilling, A. Kozian, M. Senturk et al., "Effects of volatile and intravenous anesthesia on the alveolar and systemic inflammatory response in thoracic surgical patients," Anesthesiology, vol. 115 , no. 1, pp. 65-74, 2011.

[76] T. A. Crozier, J. E. Müller, D. Quittkat, M. Sydow, W. Wuttke, and D. Kettler, "Effect of anaesthesia on the cytokine responses to abdominal surgery," British Journal of Anaesthesia, vol. 72, no. 3, pp. 280-285, 1994.

[77] X. Shen, N. Bhatt, J. Xu et al., "Effect of isoflurane on myocardial energetic and oxidative stress in cardiac muscle from Zucker diabetic fatty rat," Journal of Pharmacology and Experimental Therapeutics, vol. 349, no. 4, pp. 21-28, 2014.

[78] J.-T. Li, H. Wang, W. Li et al., "Anesthetic isoflurane posttreatment attenuates experimental lung injury by inhibiting inflammation and apoptosis," Mediators of Inflammation, vol. 2013, Article ID 108928, 16 pages, 2013.

[79] A. Kojima, H. Kitagawa, M. Omatsu-Kanbe, H. Matsuura, and S. Nosaka, "Sevoflurane protects ventricular myocytes against oxidative stress-induced cellular $\mathrm{Ca}^{2+}$ overload and hypercontracture," Anesthesiology, vol. 119, no. 3, pp. 606-620, 2013.

[80] N. R. Van Allen, P. R. Krafft, A. S. Leitzke, R. L. Applegate, J. Tang, and J. H. Zhang, "The role of volatile anesthetics in cardioprotection: a systematic review," Medical Gas Research, vol. 2, article 22, 2012.

[81] W. Li, X. Wang, M. He et al., "Activating $\mathrm{Na}^{+}-\mathrm{K}^{+}$ATPase: a potential cardioprotective therapy during early hemorrhagic shock," Medical Hypotheses, vol. 83, no. 6, pp. 685-687, 2014.

[82] C. Nigro Neto, M. A. Tardelli, and P. H. D. Paulista, "Use of volatile anesthetics in extracorporeal circulation," Revista Brasileira de Anestesiologia, vol. 62, no. 3, pp. 346-355, 2012. 
[83] C. Kanellopoulou and S. Monticelli, "A role for microRNAs in the development of the immune system and in the pathogenesis of cancer," Seminars in Cancer Biology, vol. 18, no. 2, pp. 79-88, 2008.

[84] J. A. Weber, D. H. Baxter, S. Zhang et al., "The microRNA spectrum in 12 body fluids," Clinical Chemistry, vol. 56, no. 11, pp. 1733-1741, 2010.

[85] B. Yang, X. Kang, Y. Xing et al., "Effect of microRNA-145 on IL- $\beta$-induced cartilage degradation in human chondrocytes," FEBS Letters, vol. 588, no. 14, pp. 2344-2352, 2014.

[86] C. Mistrellides, K. Lunnon, M. Sattlecker et al., "MicroRNA biomarkers in Alzheimer's disease," Alzheimer's \& Dementia, vol. 9, no. 4, supplement, p. P224, 2013.

[87] G. Cheng, "Circulating miRNAs: roles in cancer diagnosis, prognosis and therapy," Advanced Drug Delivery Reviews, vol. 81, pp. 75-93, 2015.

[88] J. Kim, B. Kim, D. Kim et al., "Effect of propofol on microRNA expression profile in adipocyte-derived adult stem cells," Chonnam Medical Journal, vol. 50, no. 3, pp. 86-90, 2014.

[89] S. Tanaka, M. Ishikawa, M. Arai, Y. Genda, and A. Sakamoto, "Changes in microRNA expression in rat lungs caused by sevoflurane anesthesia: a TaqMan low-density array study," Biomedical Research, vol. 33, no. 5, pp. 255-263, 2012.

[90] D. M. Twaroski, Y. Yan, J. M. Olson, Z. J. Bosnjak, and X. Bai, "Down-regulation of microRNA-21 is involved in the propofolinduced neurotoxicity observed in human stem cell-derived neurons," Anesthesiology, vol. 121, no. 4, pp. 786-800, 2014.

[91] J. D. Adams Jr., T. A. Baillie, A. J. Trevor, and N. Castagnoli Jr., "Studies on the biotransformation of ketamine 1-identification of metabolites produced in vitro from rat liver microsomal preparations," Biomedical Mass Spectrometry, vol. 8, no. 11, pp. 527$538,1981$.

[92] E. Erturk, S. Topaloglu, D. Dohman et al., "The comparison of the effects of sevoflurane inhalation anesthesia and intravenous propofol anesthesia on oxidative stress in one lung ventilation," BioMed Research International, vol. 2014, Article ID 360936, 4 pages, 2014.

[93] O. M. E. Abdel-Salam, E. R. Youness, N. A. Mohammed, E. A. Omara, and A. A. Sleem, "Effect of ketamine on oxidative stress following lipopolysaccharide administration," Comparative Clinical Pathology, vol. 24, pp. 53-63, 2015.

[94] B. Sinner, O. Friedrich, W. Zink, Y. Zausig, and B. M. Graf, “The toxic effects of $S(+)$-ketamine on differentiating neurons in vitro as a consequence of suppressed neuronal Ca2+ oscillations," Anesthesia and Analgesia, vol. 113, no. 5, pp. 1161-1169, 2011.

[95] S. Lessans and S. G. Dorsey, "The role for epigenetic modifications in pain and analgesia response," Nursing Research and Practice, vol. 2013, Article ID 961493, 6 pages, 2013.

[96] C. Tsompos, C. Panoulis, K. Toutouzas, G. Zografos, and A. Papalois, "The effect of the antioxidant drug "U-74389G" on haemoglobin levels following a hypoxemia/re-oxygenation protocol in rats," The Journal of Critical Care Medicine, vol. 1, no. 3, pp. 102-106, 2015.

[97] E. Crimi, F. S. Taccone, T. Infante, S. Scolletta, V. Crudele, and C. Napoli, "Effects of intracellular acidosis on endothelial function: an overview," Journal of Critical Care, vol. 27, no. 2, pp. 108-118, 2012.

[98] B. R. Collier, A. Giladi, L. A. Dossett, L. Dyer, S. B. Fleming, and B. A. Cotton, "Impact of high-dose antioxidants on outcomes in acutely injured patients," Journal of Parenteral and Enteral Nutrition, vol. 32, no. 4, pp. 384-388, 2008.
[99] R. Fukushima and E. Yamazaki, "Vitamin C requirement in surgical patients," Current Opinion in Clinical Nutrition \& Metabolic Care, vol. 13, no. 6, pp. 669-676, 2010.

[100] K. R. Saad, P. F. Saad, L. D. Filho et al., "Pulmonary impact of Nacetylcysteine in a controlled hemorrhagic shock model in rats," Journal of Surgical Research, vol. 182, no. 1, pp. 108-115, 2013.

[101] I. Inci, W. Zhai, S. Arni, S. Hillinger, P. Vogt, and W. Weder, "Nacetylcysteine attenuates lung ischemia-reperfusion injury after lung transplantation," Annals of Thoracic Surgery, vol. 84, no. 1, pp. 240-246, 2007.

[102] H.-X. Zhang, G.-L. Duan, C.-N. Wang, Y.-Q. Zhang, X.-Y. Zhu, and Y.-J. Liu, "Protective effect of resveratrol against endotoxemia-induced lung injury involves the reduction of oxidative/nitrative stress," Pulmonary Pharmacology and Therapeutics, vol. 27, no. 2, pp. 150-155, 2014.

[103] O. Benedek, M. Veres, and M. Dobreanu, "Neutrophil viability as a clinical outcome marker in mechanically ventilated critically ill trauma patients: a case series," The Journal of Critical Care Medicine, vol. 1, no. 3, pp. 113-117, 2015. 

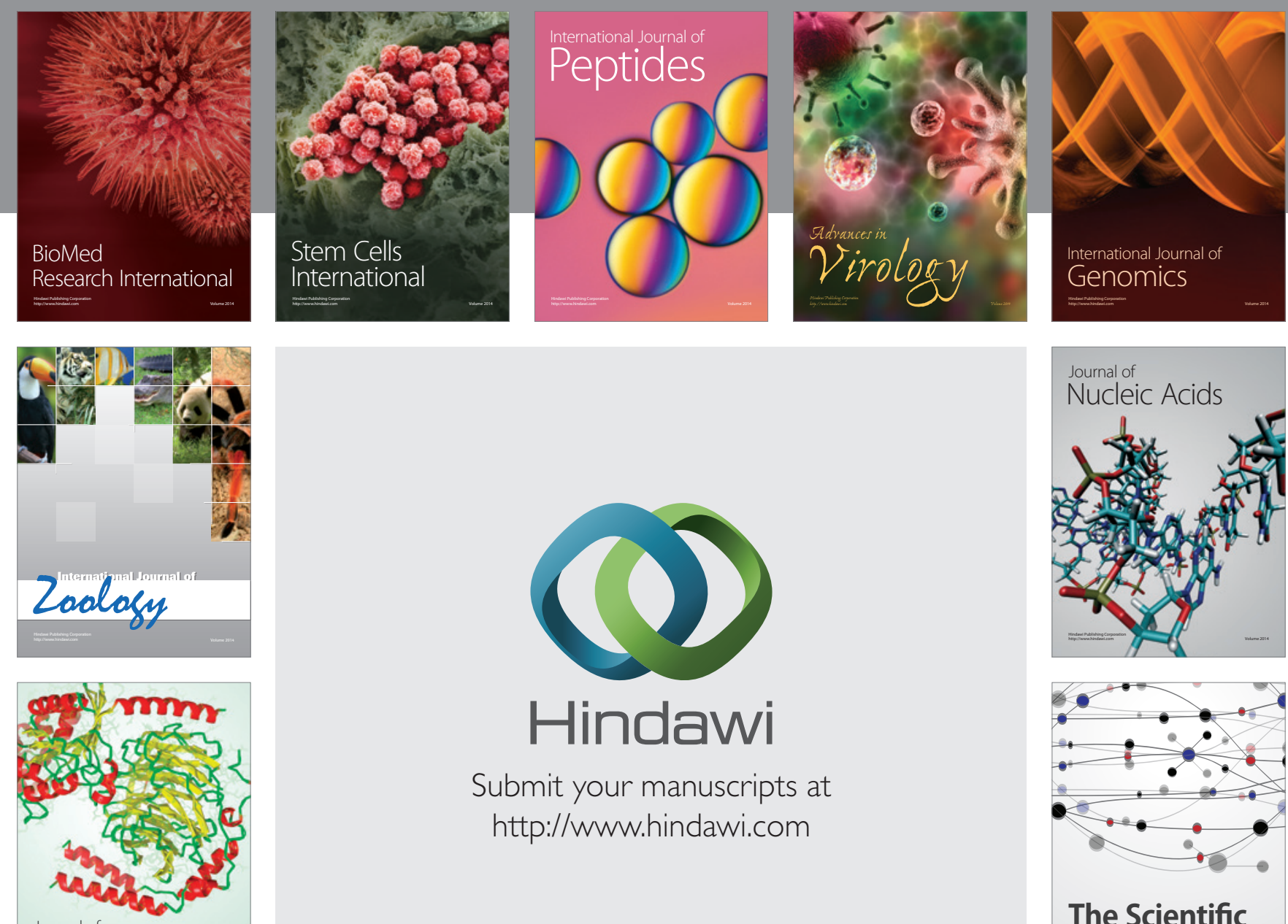

Submit your manuscripts at

http://www.hindawi.com

Journal of
Signal Transduction
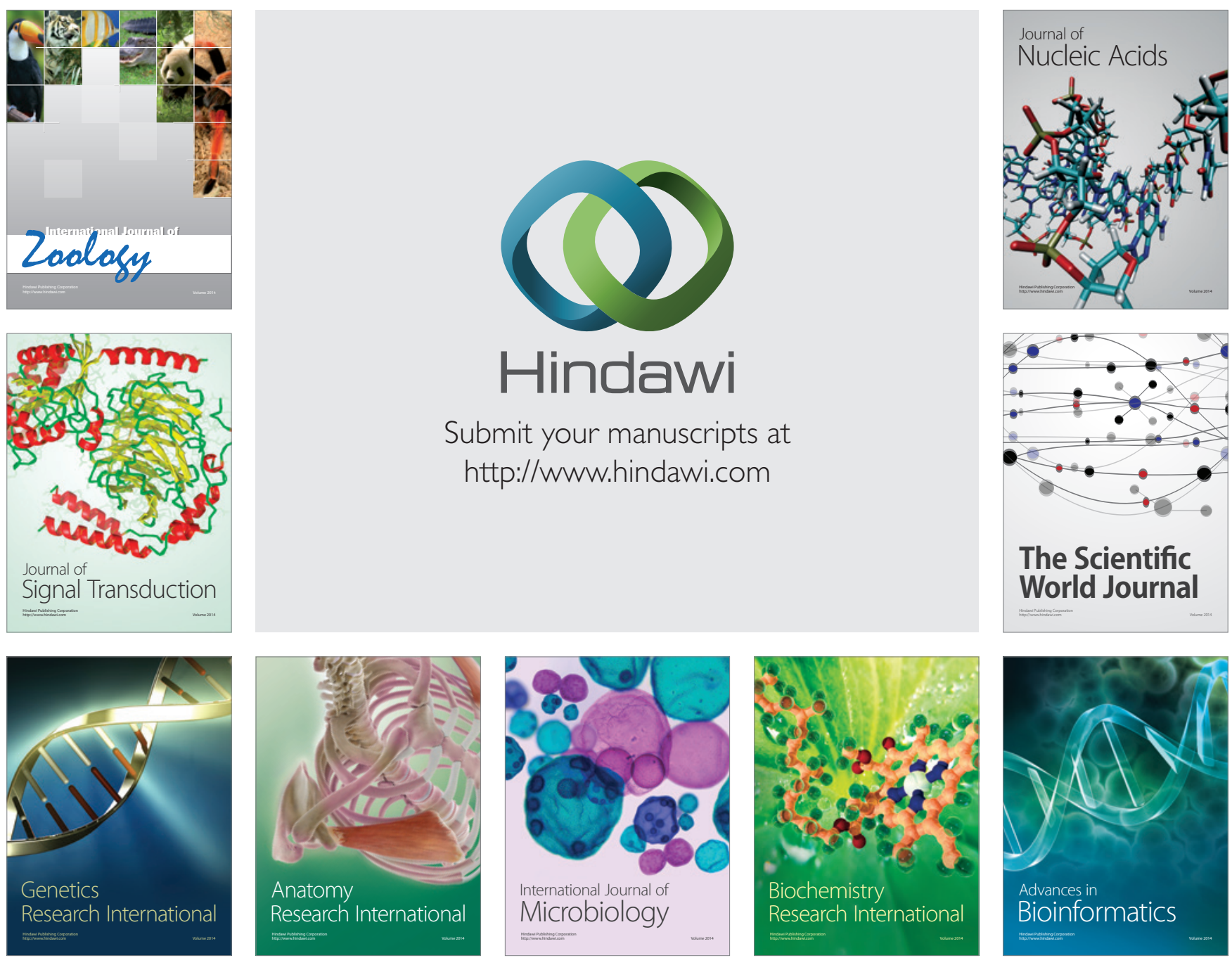

The Scientific World Journal
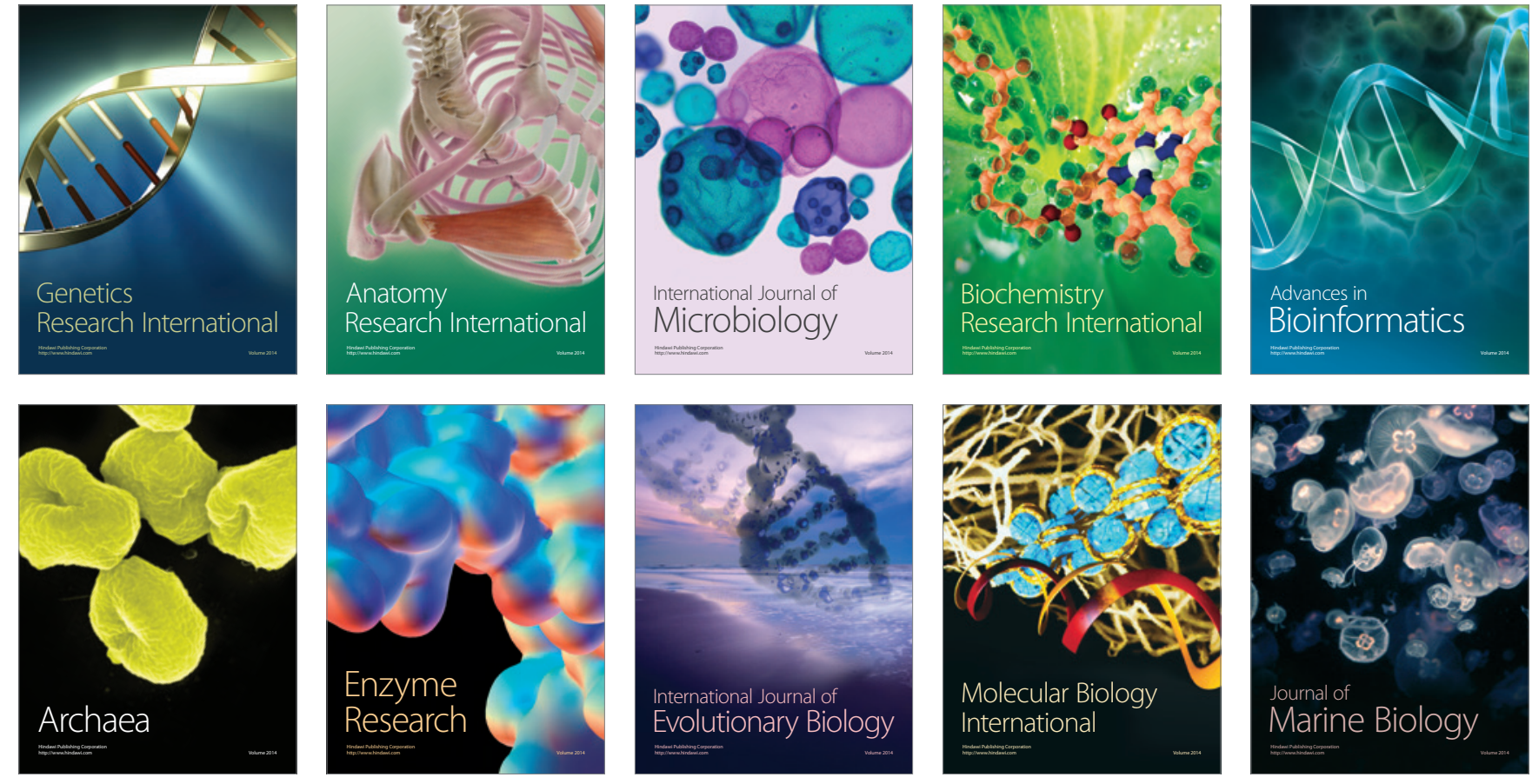